\title{
Growth and epiphytic behavior of three Gambierdiscus species (Dinophyceae) associated with various macroalgal substrates
}

Nurin Izzati Mustapa ', Hwa Lin Yong ', Li Keat Lee ', Zhen Fei Lim', Hong Chang Lim 2$^{2}$ S Sing Tung Teng 3, Zhaohe Luo 4, Haifeng Gu 4, Chui Pin Leaw 5, Po Teen Lim Affiliations expand

- PMID: 31672230

DOI: 10.1016/j.hal.2019.101671

\section{Abstract}

Species of the benthic dinoflagellate Gambierdiscus produce polyether neurotoxins that caused ciguatera fish/shellfish poisoning in human. The toxins enter marine food webs by foraging of herbivores on the biotic substrates like macroalgae that host the toxic dinoflagellates. Interaction of Gambierdiscus and their macroalgal substrate hosts is believed to shape the tendency of substrate preferences and habitat specialization. This was supported by studies that manifested epiphytic preferences and behaviors in Gambierdiscus species toward different macroalgal hosts. To further examine the supposition, a laboratory-based experimental study was conducted to examine the growth, epiphytic behaviors and host preferences of three Gambierdiscus species towards four macroalgal hosts over a culture period of 40 days. The dinoflagellates Gambierdiscus balechii, G. caribaeus, and a new ribotype, herein designated as Gambierdiscus type 7 were initially identified based on the thecal morphology and molecular characterization. Our results showed that Gambierdiscus species tested in this study exhibited higher growth rates in the presence of macroalgal hosts. Growth responses and attachment behaviors, however, differed among different species and strains of Gambierdiscus over different macroalgal substrate hosts. Cells of Gambierdiscus mostly attached to substrate hosts at the beginning of the experiments but detached at the later time. Localized Gambierdiscus-host interactions, as 
demonstrated in this study, could help to better inform efforts of sampling and monitoring of this benthic toxic dinoflagellate.

Keywords: Ciguatera; Gambierdiscus balechii; Gambierdiscus caribaeus; Habitat preference; Harmful algal blooms.

Copyright $@ 2019$ Elsevier B.V. All rights reserved. 